\title{
BEHAVIOUR OF FIBRE REINFORCE CONCRETE BEAM IN COMBINED BENDING AND TORSION
}

\author{
C.Arvind Kumar ${ }^{1}$, Madan Mohan ${ }^{2}$, D.V.S.P Rajesh ${ }^{3}$, Prathik Kulkarni ${ }^{4}$ \\ ${ }^{1}$ Assistant professor, Civil Engineering, Guru Nanak Institution \& Technical Campus, Telengana, India \\ ${ }^{2}$ Professor, Civil Engineering, Guru Nanak Institute Technology, Telengana, India \\ ${ }^{3}$ Assistant Professor, Civil Engineering, Guru Nanak Institution \& Technical Campus, Telengana, India \\ ${ }^{4}$ Assistant Professor, Civil Engineering, Guru Nanak Institution \& Technical Campus, Telengana, India
}

\begin{abstract}
In structures where equilibrium torsion occurs, in addition to shear and flexure, torsion should be calculated and designed for torsional strength of sections. The phenomenon of torsion seldom occurs by itself. It is almost invariably combined with other actions such as flexure and shear. Hence it is combined torsion and bending which is of real practical interest. In this work combined bending and torsion has been considered for the fibre reinforced concrete beams by taking the different percentage of fibre volume. The glass fibres are used for the investigation. This would seem to justify large number of investigations dealing with pure torsion of concrete members.

In present research, an attempt is made to study the following aspects: Behaviour of reinforced concrete beam under. 1)Combined bending and torsion, (a)Without glass fibres (b)With glass fibres 2)The effect of increase of fibre percentage on torsional resistance of beam. 3) To develop torque. Vs. twist relation of the beams. The experimental program consists of casting 4 reinforced concrete beams of size $150 \mathrm{~mm} X 150 \mathrm{~mm}$ and length $2 \mathrm{~m}$. Two of them were cast without fibres to make a comparative study with the remaining 3 beams; one beam is cast with $0.5 \%$ fibre by weight, one beam $1.0 \%$ fibre by weight in the rest one beam $1.5 \%$ fibre by weight added. The longitudinal reinforcement, spacing of shear stirrups is kept constant.
\end{abstract}

Keywords: Aspect ratio, Glass Fibres, Reinforced concrete, Beam, Torsional strength, Point load.

\section{INTRODUCTION}

When a beam is transversely loaded in such a manner that the resultant force passes through the longitudinal shear centre axis, the beam only bends and no torsion will occur. When the resultant acts away from the shear centre axis, then the beam will not only bend but also twist. [1]

In practical reinforced-concrete construction, torsion usually occurs as a secondary effect of bending. Members subject to combined bending and torsion should normally be designed in the same way as sections subject to combined bending and shear, which is a similar problem. The section should be proportioned to resist the bending moment, and additional torsional shear reinforcement should then be introduced if the torsional resistance of the section is inadequate.

When the twisting moment was dominant the initial crack occurred at the middle of the north face where the shear stresses due to torsion and flexure shear where additive.

The inclination of these initial cracks was nearly $45^{\circ}$ to the axis of the beam. The cracks propagated towards the top with increasing angle of inclination and bottom faces. The beam at the ultimate stage formed a hinge along the four face, which is the compression face. This face is free from cracks.
The hinge connected to ends of only one of the several cracks transferring the three faces. With further loading the concrete began to crush along the compression hinge and failure occurred.

\subsection{Strengthening of Beams}

For torsional strengthening, there are many methods such as: section enlargement, stirrup spacing decreasing, external post tensioning method, addition of fibres to concrete etc. While many methods of strengthening structures are available, strengthening structures by adding fibre is one of the advanced techniques. During the past decade, their application in this field has been rising due to the wellknown advantages of FRP composites over other materials. Consequently, a great quantity of research, both experimental and theoretical, has been conducted on the behaviour of FRP-strengthened reinforced concrete (RC) structures. In this regard, the evolving technology of using carbon-bonded fibre-reinforced polymers (CFRP) for strengthening of $\mathrm{RC}$ beams has attracted much attention in recent years.

\subsection{Fibre Reinforced Concrete [2]}

In the plain concrete and similar brittle materials, structural cracks develop even before loading, particularly due to drying shrinkage or other causes of volume change. The width of these cracks seldom exceeds a few microns, but 
their other two dimensions maybe of higher magnitude. When loaded, the micro cracks propagate and open up, and owing to the effect of stress concentration, addition a crack form in places of minor defects. The structural cracks proceed slowly or by tiny jumps because various obstacles retard them, changes of direction in by passing the more resistant grains in matrix. The development of such micro cracks is the main cause of inelastic deformation in concrete.

\subsection{Types of Fibres [2]}

Depending upon the parent material used for manufacturing fibres can be broadly classified as;

1. Metallic fibres (e.g. low carbon steel, stainless steel, galvanized iron, aluminum)

2. Mineral fibres (carbon, glass, asbestos etc.)

3. Synthetic fibres (polypropylene, polyethylene, polyester, nylon etc.)

4. Natural fibres (bamboo, coir, jute, sisal, wood, sugarcane bagasse etc.)

\subsection{Glass Fibres}

Glass fibre (or glass fiber) is a material consisting of numerous extremely fine fibres of glass. Glassmakers throughout history have experimented with glass fibres, but mass manufacture of glass fibre was only made possible with the invention of finer machine tooling. In 1893, Edward Drummond Libbey exhibited a dress at the World's Columbian Exposition incorporating glass fibres with the diameter and texture of silk fibres. This was first worn by the popular stage actress of the time Georgia Cayvan. Glass fibres can also occur naturally, as Pele's hair. Glass fibre is formed when thin strands of silica-based or other formulation glass are extruded into many fibres with small diameters suitable for textile processing. The technique of heating and drawing glass into fine fibres has been known for millennia; however, the use of these fibres for textile applications is more recent. Until this time, all glass fibre had been manufactured as staple (that is, clusters of short lengths of fibre).

Table 1 Specification of Glass Fiber

\begin{tabular}{|l|l|l|l|}
\hline Length & Shape & Diameter & Aspect Ratio \\
\hline $12 \mathrm{~mm}$ & Round & $0.01386 \mathrm{~mm}$ & 865.27 \\
\hline
\end{tabular}

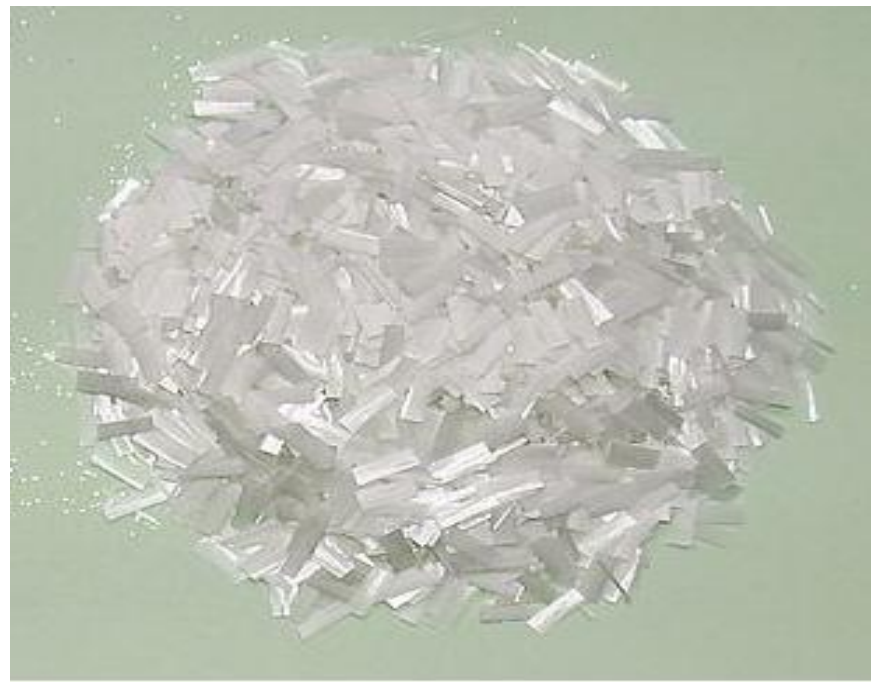

Fig -1: Glass Fibers

\section{EXPERIMENTAL PROGRAM}

The experimental program consists of casting and testing of four RCC beams of size $150 \mathrm{mmx} 150 \mathrm{mmx} 2000 \mathrm{~mm}$. Out of which three of them are glass fibre reinforced and the remaining one is without glass fibres. Within these three beams, one beam is cast with glass(FR 0 ) fibres of $0.5 \%$ by weight(FR 0.5$), 2^{\text {nd }}$ beam of $1.0 \%$ by weight(FR 1$)$ and $3^{\text {rd }}$ one with $1.5 \%$ by weight(FR 1.5). All the beams were tested to study the effects of combined bending and torsion.

\subsection{Proportioning of Beam Specimen}

The flexural reinforcement consisted of two $8 \mathrm{~mm}$ diameter bars at the bottom and two $8 \mathrm{~mm}$ diameter bars at the top of the beam used as anchor bars. Shear reinforcement was provided in the form of two-legged rectangular stirrups with standard hooks. Stirrups were made of $6 \mathrm{~mm}$ diameter bars. The stirrups were $100 \mathrm{~mm}$ wide and $100 \mathrm{~mm}$ in depth. The center to center spacing of the stirrups was $180 \mathrm{~mm}$.[8][9]

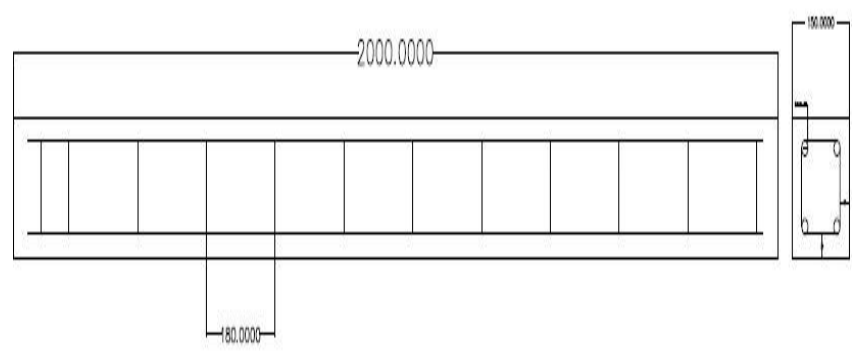

Fig-2 : Details of beam

\subsection{Materials}

The M 20 grade of concrete was used for the casting of RC and RFRC beams. An Ordinary Portland Cement (OPC) of $53 \mathrm{MPa}$ strength, locally available river sand as fine aggregate, crushed stone aggregate with a maximum particle size of $20 \mathrm{~mm}$ as coarse aggregate, Glass fibres and potable water were used in this investigation. The mix proportion obtained from these materials is given in table below; 
Table 2 Mix Proportions for M 20

\begin{tabular}{|l|l|l|l|}
\hline Water & Cement & $\begin{array}{l}\text { Fine } \\
\text { Aggregate }\end{array}$ & $\begin{array}{l}\text { Coarse } \\
\text { Aggregate }\end{array}$ \\
\hline $186 \mathrm{~kg}$ & $454 \mathrm{~kg}$ & $681 \mathrm{~kg}$ & $1362 \mathrm{~kg}$ \\
\hline 0.45 & 1 & 1.5 & 3 \\
\hline
\end{tabular}

$\therefore$ Mix Proportion is $1: 1.5: 3[6]$

\subsection{Designation of the Beams}

Table 3 Beam Casting Schedule

\begin{tabular}{|l|l|l|}
\hline Beam Type & Designation & $\begin{array}{l}\text { Fiber } \\
(\%)\end{array}$ \\
\hline $\begin{array}{l}\text { Reinforced } \\
\text { Concrete }\end{array}$ & $\begin{array}{l}\text { Fibre Reinforced } \\
\text { FR 0 }\end{array}$ & 0 \\
\hline Glass FRC & FR 0.5 & 0.5 \\
\hline Glass FRC & FR 1 & 1 \\
\hline Glass FRC & FR 1.5 & 1.5 \\
\hline
\end{tabular}

\subsection{Set Up and Testing Procedure}

All the beams were tested for torsion under UTM of $400 \mathrm{kN}$ in the strength of materials lab of GNI engineering college Hyderabad. The three samples of each type of beam specimen were tested.

The test is conducted on UTM using locally fabricated load transfer equipment. The setup is shown in fig.5. The beam was placed on two cubes, which were placed on UTM platform. The beams are simply supported on concrete cubes. Arms were fixed at either end of the beam. A crossbeam is placed such that it rests on two ends of the arms without touching the beam. The torque was applied through this cross beam applying load from UTM at the center of this cross beam and also a point load of was $1 \mathrm{kNapplied}$ from the Centre of the beam using hydraulic jack. Dial gauges were fixed at the selected points.

\subsubsection{Sequence of Loading}

First crossbeam was made just in touch with the loading frame of UTM. This point load $(1 \mathrm{kN})$ is applied at the center of the beam using hydraulic jack. Finally putting the point load constant and then the torque load is increased at every $0.1 \mathrm{kN}$ for calculation of torsional moment and the deformation observed in the dial gauge with the least count of $0.01 \mathrm{~mm}$ for the calculation of angle of twist of beam.

These increments in readings were taken throughout the test. The load was applied till the ultimate failure of beam. The deflections were taken at one end of the beam, and the torsional moment by angle of twist graph was plotted from the obtained results.

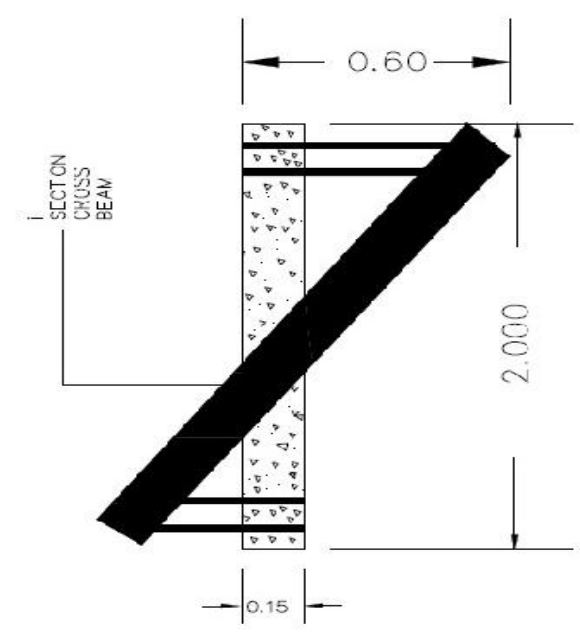

Fig -3: Plan of testing setup

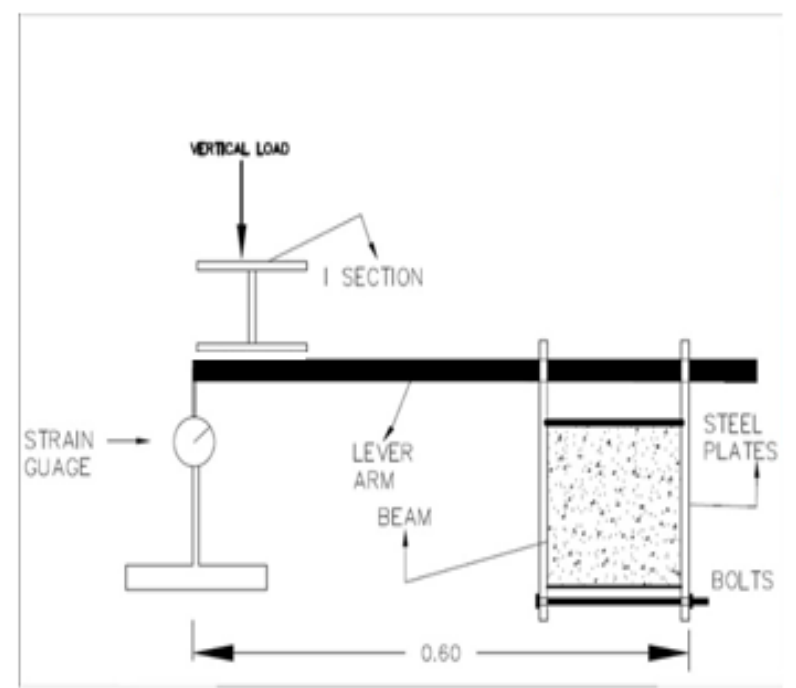

Fig -4: Schematic Test Setup at the End of Specimen

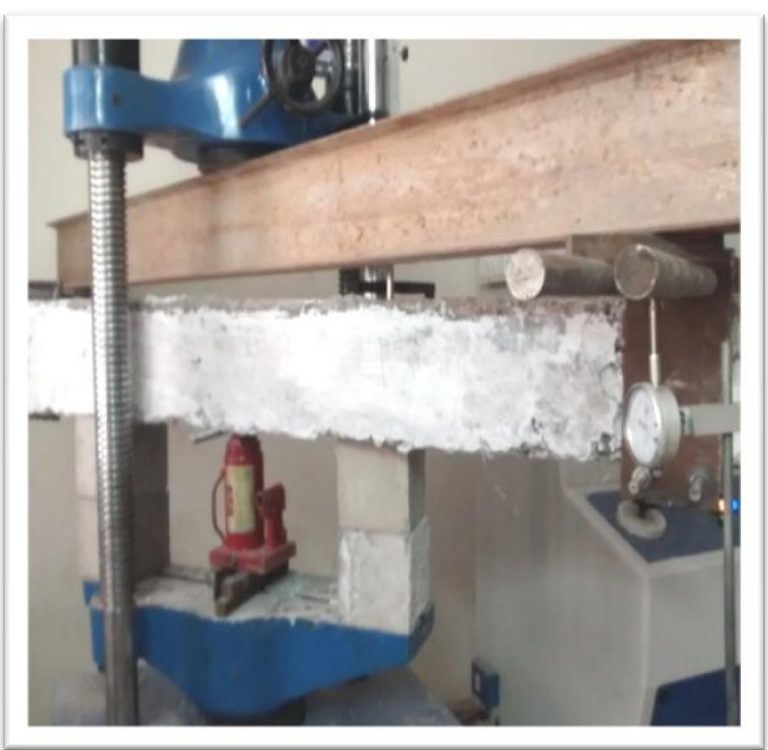

Fig -5: Experimental Setup of the Beam 


\section{RESULTS AND DISCUSSION}

The final results at cracking point and ultimate load point keeping point load of $1 \mathrm{kN}$ constant (for bending) are obtained after calculations of all the test readings.

Table 4 Test Results of cracking torque

\begin{tabular}{|l|l|l|}
\hline BEAM & $\begin{array}{l}\text { Load } \\
\mathrm{kN}\end{array}$ & $\begin{array}{l}\text { Cracking torque } \\
(\mathrm{kN}-\mathrm{M})\end{array}$ \\
\hline FR 0 & 4 & 2.916 \\
\hline FR 0.5 & 5 & 3.516 \\
\hline FR 1 & 6 & 4.116 \\
\hline FR 1.5 & 7 & 4.716 \\
\hline
\end{tabular}

Table 4 Test Results of ultimate torque

\begin{tabular}{|l|l|l|}
\hline BEAM & $\begin{array}{l}\text { Load } \\
\mathrm{kN}\end{array}$ & $\begin{array}{l}\text { Ultimate torque } \\
(\mathrm{kN}-\mathrm{M})\end{array}$ \\
\hline FR 0 & 6 & 4.116 \\
\hline FR 0.5 & 8 & 5.316 \\
\hline FR 1 & 9 & 5.916 \\
\hline FR 1.5 & 10 & 6.516 \\
\hline
\end{tabular}

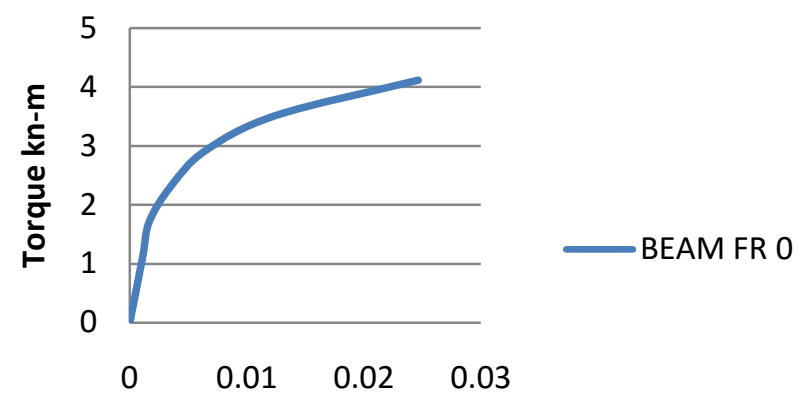

Angle of twist radians/m

Chart -1: Torque Twist response of FR 0

Chart -1: The FR 0 (control beam) failed completely in torsion at a load of $6 \mathrm{kN}$ and ultimate torque is $4.116 \mathrm{kNm}$. It was observed that cracks were appeared making an angle $50^{0}-58^{0}$ with the main beam. The cracks were developed in a spiral pattern all over the main beam which later leads to the failure of the beam in torsional shear.

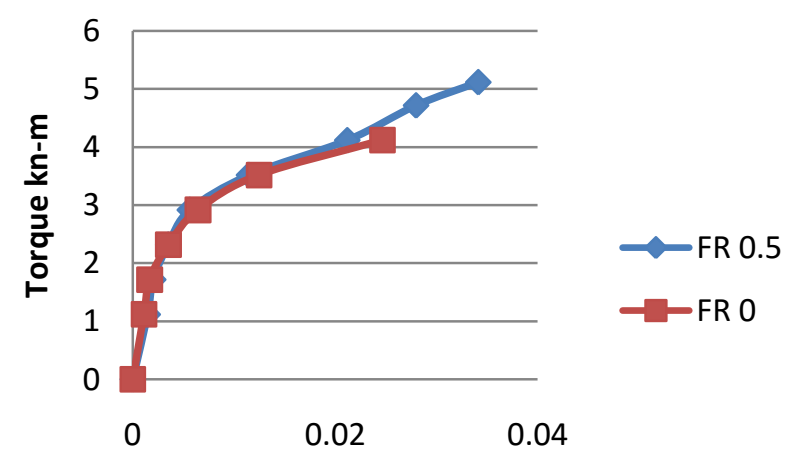

Angle twist radians/m

Chart -2: Torque Twist response of FR 0 and FR 0.5
Chart 2: The beam FR 0.5 failed completely in torsion at a load $8 \mathrm{kN}$ and ultimate torque is $5.316 \mathrm{kNm}$. The increase in the strength of beam in ultimate torque was $29.1 \%$ as compared to control beam.

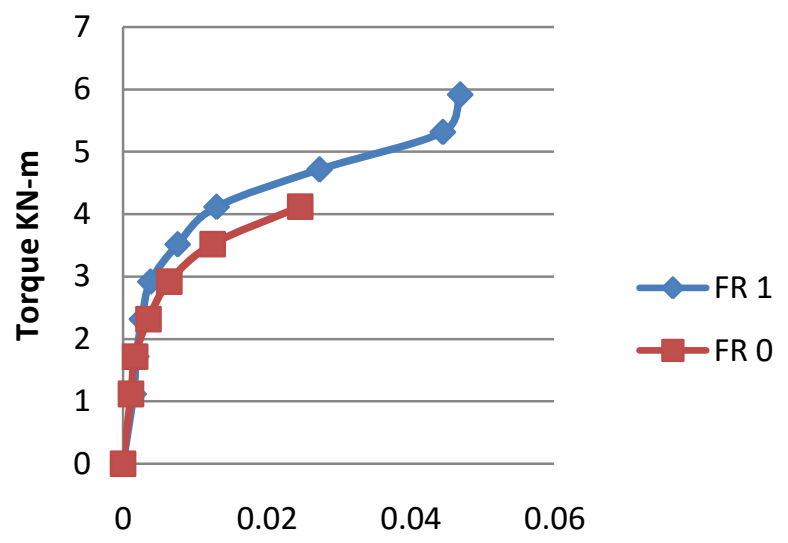

Angle of twist radians/m

Chart -3: Torque Twist response of FR 0 and FR 1

Chart -3: The beam FR 1 failed completely in torsion at a load $11 \mathrm{kN}$ and ultimate torque is $7.116 \mathrm{kNm}$. The increase in the strength of beam in ultimate torque was $20.28 \%$ as compared to control beam.

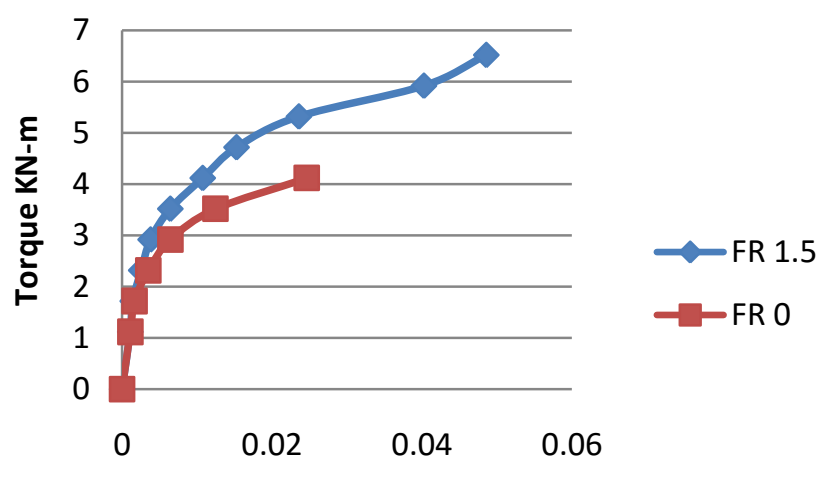

Angle of twist radians/m

Chart -4: Torque Twist response of FR 0 and FR 1.5

Chart 4: The beam FR 1.5 failed completely in torsion at a load $10 \mathrm{kN}$ and ultimate torque is $6.516 \mathrm{kNm}$. The increase in the strength of beam in ultimate torque was $58.3 \%$ as compared to control beam. 


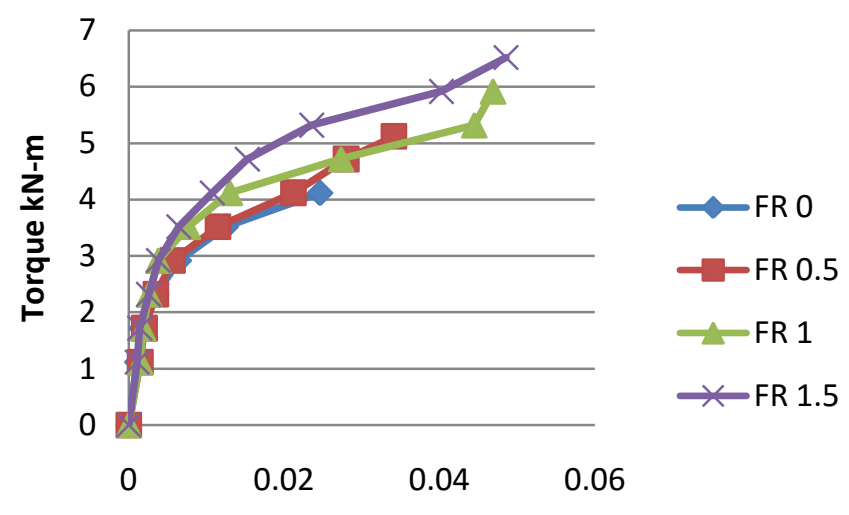

Angle of Twist in radians/m

Chart -5: Torque Twist response of FR 0, FR 0.5, FR 1 and FR 1.5

Chart 5: It is clear that FR 1.5 beam which strengthen with $1.5 \%$ glass fiber fraction experienced largest value of torsional moment (torque) and angle of twist up to the failure of beam.

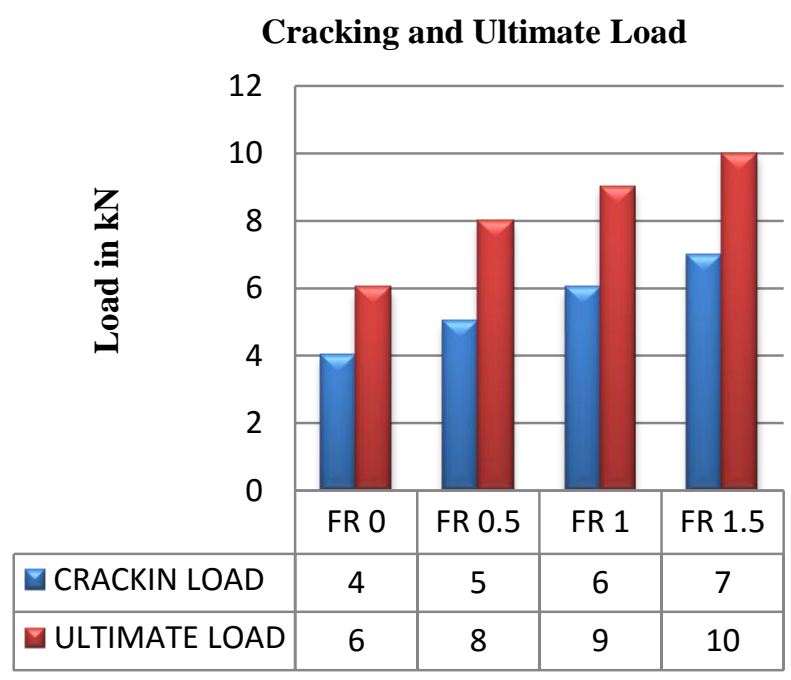

Chart-6 Variation of Cracking load and ultimate load

Above bar diagram shows the cracking and ultimate load taking strength for all glass fibre reinforced beams with respect to FR 0 (control beam), and is observed that FR 1.5 gives maximum cracking and torsional load compared with FR0, FR 0.5 and FR 1.

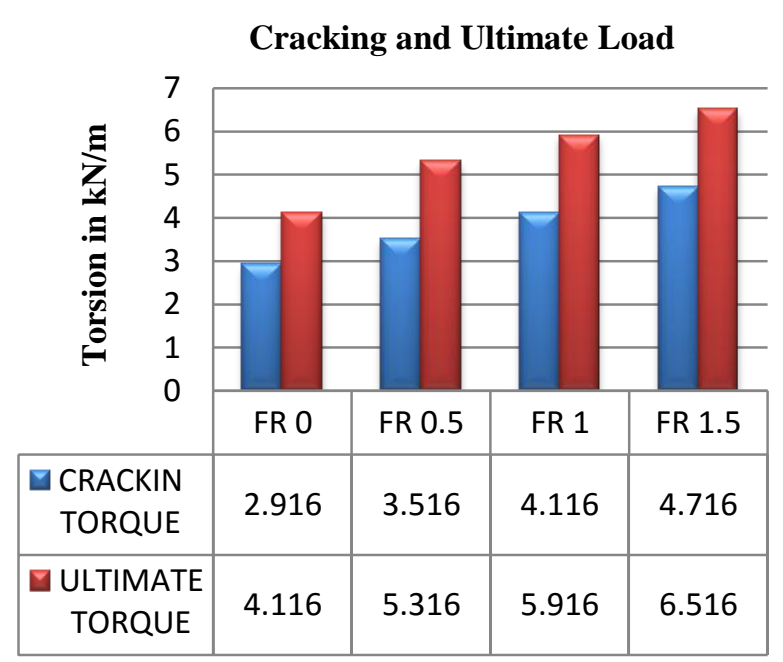

Chart-7 Variation of Cracking Torque and ultimate torque

Above bar diagram shows the cracking and ultimate torsional strength for all glass fibre reinforced beams with respect to FR 0 (control beam), and is observed that FR 1.5 gives maximum cracking and torsional strength compared with FR0, FR 0.5 and FR 1.

\section{CONCLUSIONS}

From the results obtained following conclusion is drawn;

- Use of fibre has found very beneficial to increase the torsional strength of $\mathrm{RC}$ beam subjected to combined bending and torsion.

- It is observed angle of crack increases with increase in fibre percentage.

- The cracking torsional strength of FR 1.5 increased upto $61.7 \%$ which is very significant increase in the strength of concrete compared to conventional RC Beam.

- $\quad$ The ultimate torsional strength of FR 1.5 increased upto $58.3 \%$ which is very significant increase in the strength of concrete compared to conventional RC Beam.

- $\quad$ The fibre reinforced concrete brittleness in decreased and increase in ductility can be observed.

- The fibre reinforcement has also succeeded to increase stiffness of the beam by decrease the angle of twist of strengthen beam compared to conventional RC beam.

- $\quad$ The initial crack pattern has observed at higher loads in the fibre reinforced strengthen beams.

\section{ACKNOWLEDGEMENTS}

I am very thankful to Dr. Veeranna, Director of Guru Nanak Institutional Campus for his guidance and support till end.

\section{REFERENCES}

[1]. Sukontasukkul P. (2004). "Toughness evaluation of steel and polypropylene fibre reinforced concrete beams under bending", Thammasat Int. J. Tech., Vol. 9, Part 3, pp. $35-41$. 
[2]. C.Arvind Kumar, Madan Mohan,(2015)Behaviour of fibre reinforced concrete beam in pure torsion. IJRET: International Journal of Research in Engineering and Technology, Volume: 04 Issue: 05 | May-2015

[3]. Krishna Rao MV., Dakhshina Murthy NR., Santhosh Kumar V. (2011). "Behaviour of polypropylene fibre reinforced fly ash concrete deep beams in flexure and shear", Asian Journal of Civil Engineering (Building And Housing), Vol. 12, Part 2, pp. 143-154.

[4]. Sable K. S. and Rathi M. K. (2012). "Comparison of normal compacted concrete and self-compacted concrete in shear \& torsion", International Journal of Computer Technology and Electronics Engineering, Vol. 2, Part 4, pp. 74-79.

[5]. C.D. Code, Reinforced Concrete Beams Subjected to sustained Torque, The Structural Engineer, Vol.53, No.5, Mnay 75, pp. 215-220.

[6]. N. Krishnam Raju, Design Of Concrete Mixes, CBS Publishers and Distributors, New Delhi, 1988.

[7]. IS 456:2000,

\section{BIOGRAPHIES}

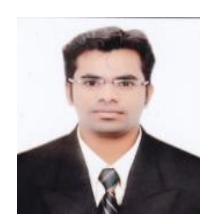

C. Arvind Kumar, Assistant professor, Civil Engineering, Guru Nanak Institution \& Technical Campus, Telengana, India

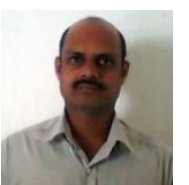

Prof. Madan Mohan, Professor, Civil Engineering, Guru Nanak Institution \& Technical Campus, Telengana, India

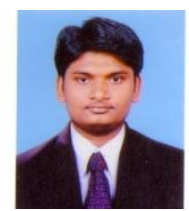

D.V.S.P Rajesh, Assistant professor, Civil Engineering, Guru Nanak Institution \& Technical Campus, Telengana, India

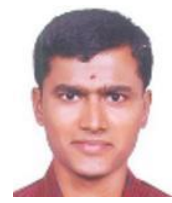

Prathik Kulkarni, Assistant professor, Civil Engineering, Guru Nanak Institution \& Technical Campus, Telengana, India 